\title{
The bearing capacity of hybrid bolted and riveted joints in steel bridge structures
}

\author{
K. Pawłowski \\ Wroctaw University of Environmental and Life Sciences, Wroctaw, Poland
}

\begin{abstract}
The aim of the research presented in this paper is to determine the influence of the way of conducting repair works of riveted joints in steel structures, where damaged or corroded rivets have to be replaced by bolts. The main research objective is to determine the bearing capacity of structures before and after reinforcement in order to create a basis for formulating the relevant conclusions concerning the safety of the structure in question.

The presented results define the influence of construction solutions that may be or are currently applied in practice, which, however, have not been confirmed yet by any model studies and computational analyses of the bearing capacity of hybrid, bolted and riveted joints. The tested elements were collected from railway bridge structures that were designated for demolition. The analysis of various arrangements of connectors in a joint was an important element of the conducted tests. According to current state of knowledge, the bearing capacity of a connector in an overlap joint, as far as bearing resistance is concerned, depends on its position in the joint. Due to that, the authors decided to test those joints, where marginal or intermediate rivets were replaced with bolts. The analysed topic is a valid issue and its scope is very wide, due to the fact that riveted steel structures that were manufactured on a mass scale more than a hundred years ago often require repairs in form of ongoing maintenance or modernisation of the structures. As riveted structures are common throughout the world, the problem applies to a multitude of objects. The conducted tests lead conclusions that partial replacement of the existing rivets with bolts has a real influence on the bearing capacity of joints in riveted structures. The degree of this influence depends on the position of the replaced connections with respect to the edge of the connected element. Nonprofessional repair works consisting in the replacement of existing, corroded rivets with new, unfitted bolts, may lead to excessive deflection of the structure. The aim of the conclusions of the paper is to provide guidelines concerning the possibility to apply hybrid, riveted and bolted joints in existing, often historic structures, where maintaining further safe operation often means preserving their cultural values, as these objects are an inseparable part of our cultural heritage.
\end{abstract}

\section{INTRODUCTION}

Steel structures have been designed and used for more than a century. As a result, many of them are approaching the end of their technical lifespan. However, due to their historic values, it is worth to maintain these structures in a proper technical condition, because they are part of our cultural heritage and proof of the technological development of our ancestors. As a result, it is necessary to renovate them. In most cases, even if a large element of the structure has to be replaced, due to various reasons, it will finally be necessary to connect the new element with existing ones. In our research we focused on the replacement of several connectors in a joint with new ones, different from those used in the original structure. This situation is even more complex, because in such event, the joint contains elements of varied bearing

DOI: $10.1201 / 9781003132134-43$ 
capacity and material characteristics. Such connection, that consists of the pre-existing rivets and newly installed bolts, may be considered a hybrid joint. The bearing capacity of a joint is a function of several factors, which makes the issue even more complex. One of these factors is the position of the connector in the joint. As the damaging mechanisms vary, for bearing resistance the position of the connector in relation to the edge of the element and to other connectors will influence the bearing capacity of the whole joint. Thus, it is important to determine the bearing capacity of the joint if a new bolt connector is added between already working connectors in form of rivets. In order to determine the influence of such works, laboratory tests were conducted on elements collected from railroad bridge structures.

\section{CHARACTERISTICS OF THE ANALYSED OBJECT}

As it has already been mentioned, the connections in historical steel structures were riveted. This resulted from technologies that were available at that time. As this was the era of dynamic development of railways, many riveted structures are the spans of railroad bridges. Obviously, other structures were also constructed in a similar way, including, e.g. steel tanks or lattice towers (including the Eiffel Tower). Tests were conducted on elements that had been cut out from the structure of the bridge span disassembled from the railway line No. 7 Warszawa Wschodnia - Dorohusk. When it was built, this line was called the Vistula Railroad. It was opened on the $19^{\text {th }}$ of August 1877 and led from Mlawa to Kowel. The bridge span from which the analysed elements were cut out was built in 1956, during the first renovation of the bridge. It was a double-girder plate girder span with the tracks down on the bridge plates. Open lattice, with crossbeams placed $2.57 \mathrm{~m}$ from each other and continuous longitudinal beams at $1.8 \mathrm{~m}$ distance. The main girders with a double-T cross-section had a total height of $2.0 \mathrm{~m}$. The structural height of the object was $1.16 \mathrm{~m}$ and the theoretical span $-18 \mathrm{~m}$. The view of the bridge is presented in Figure 1.

The tested elements were collected from bracings of longitudinal beams and main girders. These elements were selected due to the possibility to adapt them for bearing capacity tests in the universal testing machine. Additionally, the condition of riveted joints at this location was considered to be very good. Figure 2 shows the joint between the bracing and the longitudinal beams and cross-beams of the bridge span. The joint consisted of 3 rivets attached to the angle bracket being the bracing and to the node sheet metal. As the bridge span structure was relatively new (it was 63 years old at the moment of disassembly), it was in a good condition, which had a positive influence on the obtained results. No effects of corrosion or mechanical

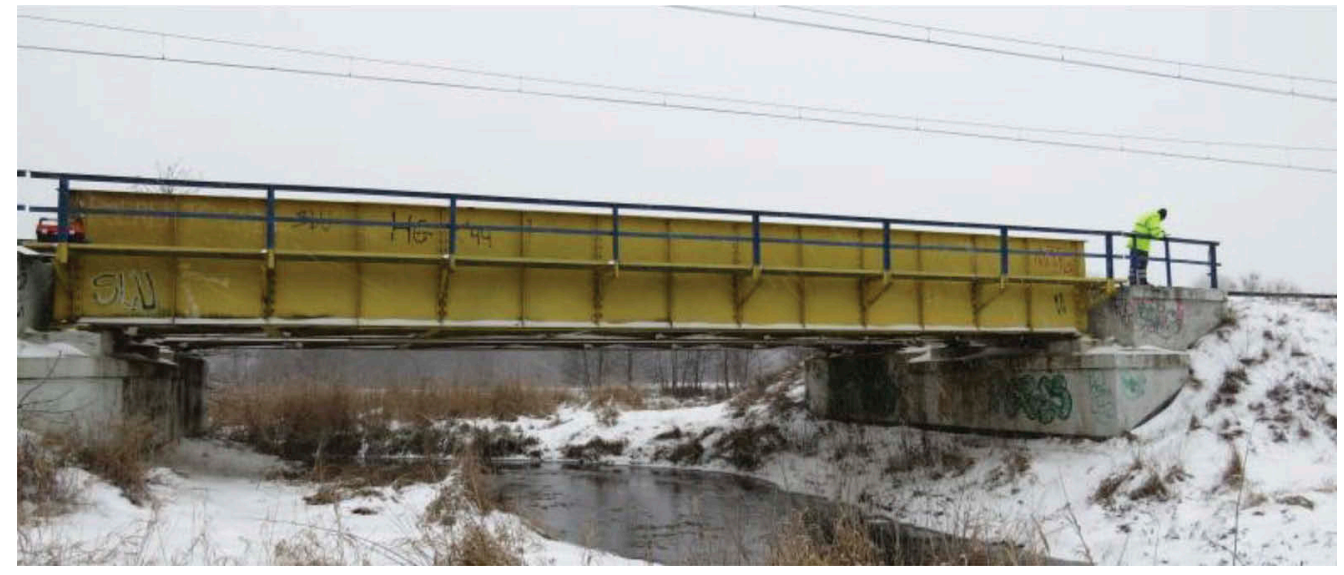

Figure 1. View of the span of the railroad bridge on $\mathrm{km} 207.887$ of the railway line No. 7 Warszawa Wschodnia - Dorohusk. 


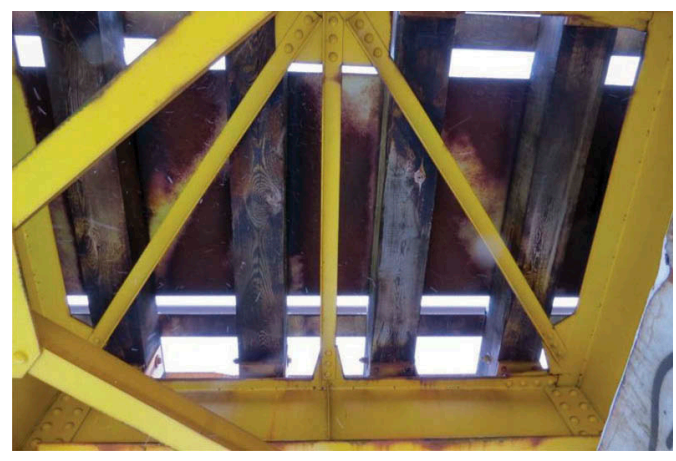

Figure 2. View of the bottom of the structure - elements, from which samples were collected.

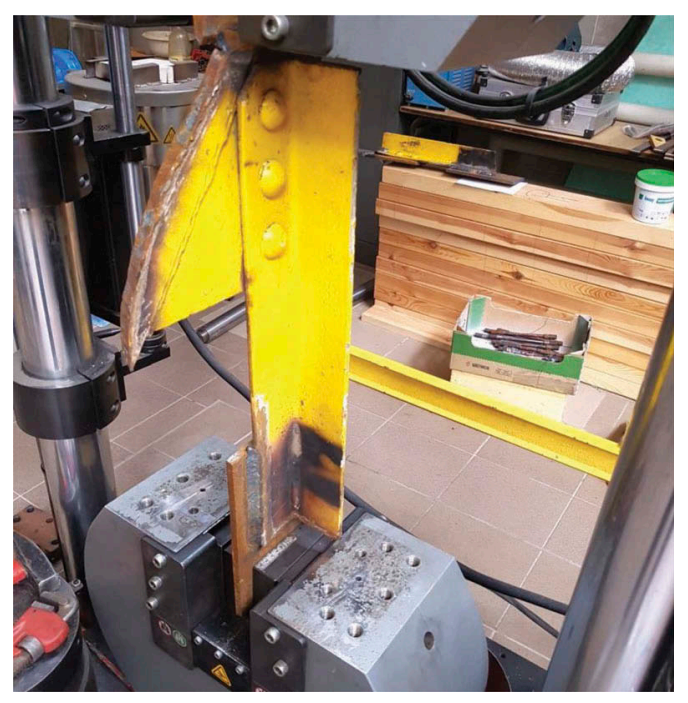

Figure 3. Element during bearing capacity tests of the riveted joint.

damages of the connecting elements were found. The replacement of the structure resulted from the modernisation of railway line No. 7 in order to adapt it to higher performance parameters.

Additionally, apart from the elements for joint testing, samples were also taken to conduct the resistance of steel. The samples were prepared in compliance with the guidelines provided in the PN-EN ISO 6892-1:2009 standard. Samples were collected from bracings of the main girders of the bridge span. Resistance tests were carried out in the Instron/SATEC KN 600 universal testing machine. Figure 3 shows the element tested for the bearing capacity of the joint, installed in the universal testing machine.

\section{RESULTS OF THE TESTS}

\subsection{Results of tensile strength tests}

The results of strength tests of steel samples are presented in Table 1. The characteristics of steel vary for different samples. The characteristics of steel from samples S.1 and S.4 are similar to those of high carbon steel, while the properties of other samples resembled those of low 
Table 1. Basic mechanical properties of steel determined in the tests of samples collected from the bridge.

\begin{tabular}{llllll}
\hline & $\mathrm{R}_{\mathrm{m}}$ & $\mathrm{R}_{\mathrm{eL}}$ & $\mathrm{R}_{\mathrm{eH}}$ & $\mathrm{R}_{\mathrm{z}}$ & $\varepsilon_{\mathrm{max}}$ \\
\cline { 2 - 6 } Sample No. & $\mathrm{MPa}$ & $\mathrm{MPa}$ & $\mathrm{MPa}$ & $\mathrm{MPa}$ & $\mathrm{mm} / \mathrm{mm}$ \\
\hline S.1 & 471 & - & - & 373 & 0.197 \\
S.2 & 446 & 286 & 301 & 361 & 0.288 \\
S.3 & 446 & 282 & 292 & 340 & 0.300 \\
S.4 & 477 & - & - & 370 & 0.220 \\
S.5 & 448 & 287 & 300 & 420 & 0.230 \\
S.6 & 446 & 270 & 287 & 333 & 0.300 \\
MIN & 446 & 270 & 287 & 333 & 0.197 \\
MAX & 477 & 287 & 301 & 420 & 0.300 \\
Average & 456 & 281 & 295 & 366 & 0.256 \\
Standard deviation & 15 & 8 & 7 & 31 & 0.045 \\
Coefficient of variation & 0.033 & 0.029 & 0.023 & 0.093 & 0.231 \\
Specific value & 428 & 266 & 282 & 302 & 0.144 \\
\hline
\end{tabular}

carbon steel. Thus, one may conclude that the steel used in historical structures was highly heterogeneous.

The characteristics used for the purposes of initial bearing capacity estimation were similar to those of S235 steel, although the average yield strength obtained in the tests was higher. However, as its mechanical properties were so heterogeneous, it was reasonable to maintain a safety margin when determining the bearing capacity of historical structures. Figure 4 shows that one of samples underwent lamellar tearing as a result of strength tests. This is additional proof of the above conclusion that the properties of construction steel used in structures from the beginning of the $20^{\text {th }}$ century are varied.

\subsection{Tests of joints}

Samples for the tests of hybrid, bolted and riveted joints were prepared in a way that ensured that they would work as lap joints. To this end, pieces of sheet metal were welded to the elements cut from the bridge structure to enable fixing them in the universal testing machine. Figure 4 shows a sample used in tests of bolted and riveted joints. Tests were conducted on 9 elements altogether. Three only riveted joints were tested as the reference group for the determination of the influence of replacing an existing rivet with a bolt. Three joints where the bolt was placed as a side connection and three joints with the bolt as an intermediate connection were tested. The hybrid joint used M16 bolts of the 5.8 class. The bolts were not fitted. The holes where rivets had been removed to be replaced by bolts had the diameter of approx. $17 \mathrm{~mm}$. The connection was not a prestressed joint.

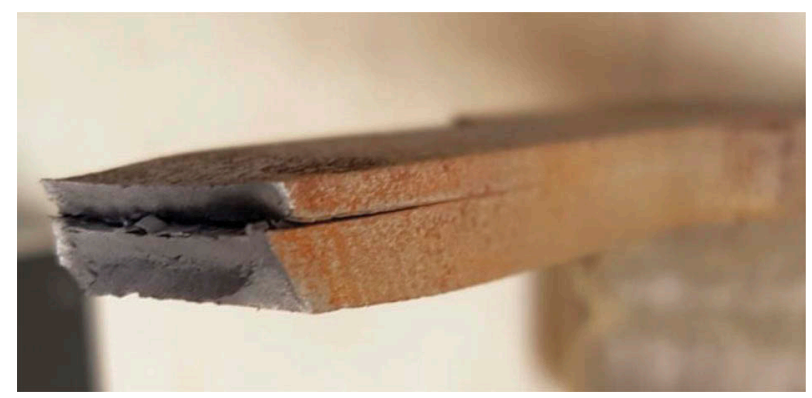

Figure 4. Steel sample that underwent lamellar tearing as a result of strength tests. 


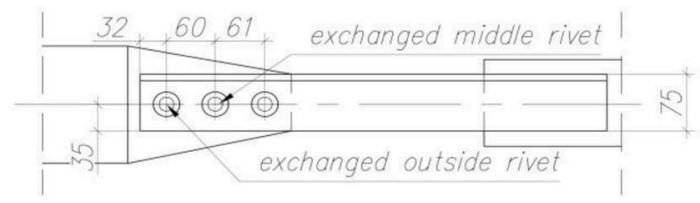

Figure 5. Drawing of the element used for bearing capacity tests of the hybrid joint.

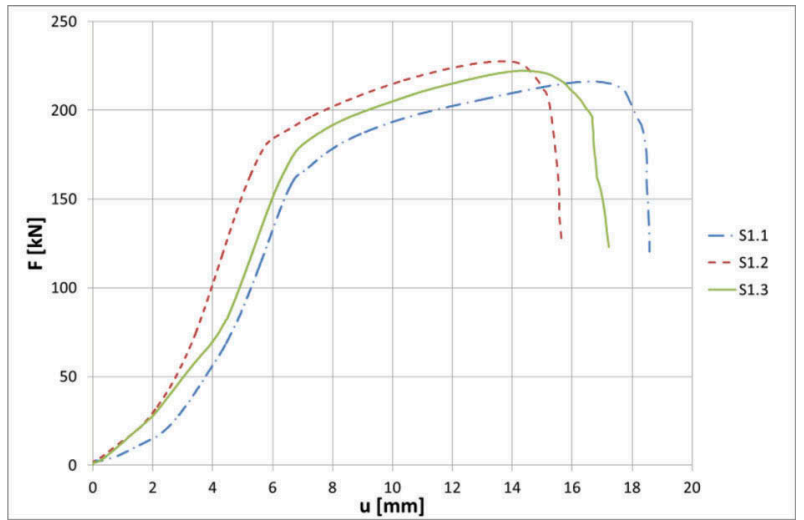

Figure 6. Diagram of the force-deformation relation for elements with 3 rivets.

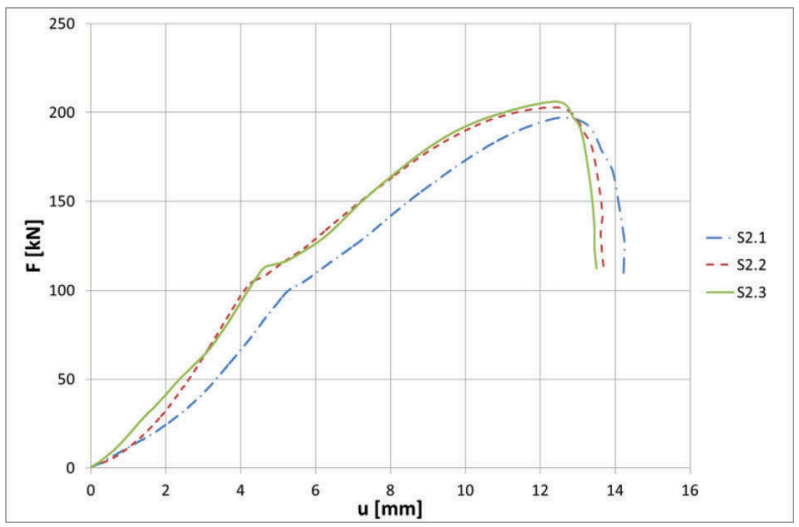

Figure 7. Diagram of the force-deformation relation for elements with 2 rivets and outside bolt.

The diagrams below show the relation between force and deformation for selected joints. The diagram in Figure 6 shows the curves for joints with 3 rivets. The subsequent two diagrams (Figures 7 and 8) show joints where, respectively, side and intermediate rivets were replaced.

The comparison of these diagrams reveals that the replacement of a rivet with a bolt in an existing structure leads to a lowered bearing capacity of the joint. However, there is a noticeable difference between joints where the outside and middle rivets were replaced. The bearing capacity of joints where outside rivets were replaced was significantly lower than that of the joints where middle rivets were replaced with bolts. The bearing capacity of the joint 


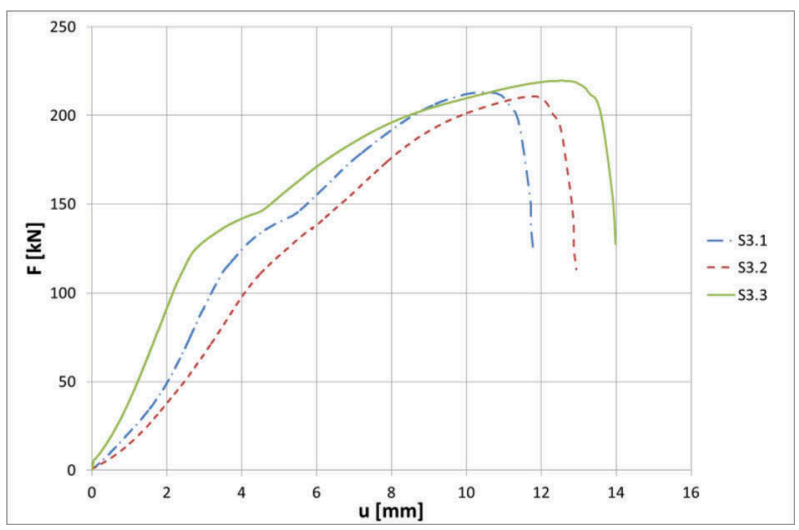

Figure 8. Diagram of the force-deformation relation for elements with 2 rivets and middle bolt.

where the middle rivet had been replaced with a bolt was $2.5 \%$ lower than that of the joint with 3 rivets. The comparison of the hybrid joint where the outside rivet had been replaced with the joint with 3 rivets revealed that the bearing capacity of the hybrid joint was $8.1 \%$ lower. Additionally, the course of the force-deformation relation was different. This results, to a great extent, from the fact that the applied bolts were not fitted. The connections were not prestressed, either. This is a result of the assumptions that were adopted for the joints discussed here. Tests on a wider group of joints are currently in progress. Further research will include joints with fitted bolts and bolts of different strength. The next stage will consist in introducing prestressed bolts, which, in the opinion of the author, should modify the characteristics of bearing capacity.

\section{CONCLUSIONS}

The conducted tests of hybrid bolt and riveted joints and the properties of the construction steel from which they were constructed lead to the following conclusions:

The tests of the construction steel of the bridge, built in 1956, demonstrated that the material was highly heterogeneous. This is important for the point of view of potential further operation of the structure. Such phenomena as lamellar tearing may be particularly dangerous when, due to the need to change the functions of the object or to reinforce it, elements are added that exert load perpendicularly to the rolling direction of sheet metal.

Partial replacement of the existing rivets with bolts has a real influence on the bearing capacity of joints in riveted structures. The degree of this influence depends on the position of the replaced connections with respect to the edge of the connected element. The presented tests revealed that the bearing capacity of a three-connection joint was approx. $2.5 \%$ lower when the middle connection was replaced. However, the bearing capacity of joints with replaced outside connection fell by over $8 \%$.

Performing repair works consisting in the replacement of existing, corroded rivets with new, unfitted bolts, may lead to excessive deflection of the structure when the nominal diameter of the selected hole ease is larger than the diameter of the bolt. In extreme cases, the rivets may be overloaded before the bolts start working, which may eventually lead to damage or failure of the whole structure.

The correlation between the bearing capacity of riveted and hybrid bolt and riveted joints taking into account the use of fitted connections, high strength connections, and prestressing of bolts is the subject of further research conducted by the author. 


\section{ACKNOWLEDGMENTS}

This work was supported by the Wrocław University of Environmental and Life Sciences (Poland) as the Ph.D. research program "Innowacyjny Naukowiec, no. NO60/0003/20"

\section{REFERENCES}

Biegus, A. 1997: Połączenia śrubowe, Warszawa-Wrocław, Wydawnictwo Naukowe PWN.

Design Manuals „Steel Building in Europe”, work carried out with a financial grant from the Research Fund for Coal and Steel of the European Community, 2013.

EN 1990, Eurocode - Basis of structural design.

EN 1993-1-1, Eurocode 3 Design of steel structures - Part 1-8: General rules and rules for buildings.

EN 1993-1-8, Eurocode 3 Design of steel structures - Part 1-8: Design of joints. 